\title{
Should interventions to treat or prevent Alzheimer's disease be tested in a population or as targeted treatment of highly selected study participants?
}

\author{
Pierre Jean Ousset, Julien Delrieu and Bruno Vellas
}

\begin{abstract}
Symptomatic treatments for Alzheimer's disease should retain a place in the advanced stages of disease since their actions on these symptoms, even if not modifying the course of disease, are critical for improving patients' comfort and reducing the burden felt by caregivers, especially those facing behavioral disorders. In mild or prodromal stages, the opportunity to act on specific pathophysiological targets should be considered. These targeted and tailored therapies have the greatest chance to be active in the early stages of disease, in the context of heterogeneous pathological mechanisms to be specified by reliable and accessible biomarkers. Finally, interventional approaches in large populations seem particularly appropriate for prevention strategies.
\end{abstract}

When implementing preventive and therapeutic strategies for neurodegenerative diseases with broad demographic bases, such as Alzheimer's disease, two options are possible: directed interventions in large populations recruited on clinical or epidemiological grounds [1], or a much more focused strategy offering targeted treatment to study participants selected on specific criteria, including those based on recently determined biomarkers [2]. The choice between these two strategies depends, of course, on the nature of the drug or intervention offered, in terms of expected impact, potential side effects and cost [3], but also on the ease of application of the selection criteria in terms of availability, acceptance, invasiveness and financial burden on the patient and society.

Drug interventions offered to large populations of Alzheimer's disease patients since the 1980s have been symptomatic treatments, including acetycholinesterase inhibitors and modulators of NMDA receptors [4]. This symptomatic treatment strategy is still widely explored by the pharmaceutical industry, particularly with regard to cholinergic drugs, although other approaches are also being developed, such as drugs acting on the histaminic

\footnotetext{
* Correspondence: ousset.pj@chu-toulouse.fr

Alzheimer's Disease Clinical Research Centre, Gérontopôle, Toulouse University Hospital, 170 avenue de Casselardit, 31059, Toulouse cedex, France
}

or serotoninergic systems, monoamine oxidase inhibitors, and so on. One obvious advantage of this type of strategy is to offer a therapeutic opportunity to a large number of subjects without the implementation of cumbersome and expensive means of selection. The selection of these populations is, in fact, on the basis of standard clinical criteria [5] or, in the case of preventive measures, on the presence of clearly identified and easy to spot risk factors (memory complaints, vascular risk factors, and so on). This type of intervention requires that we have drugs or treatments whose efficacy has been successfully demonstrated on the same type of population; that is, by large phase III clinical trials of sufficient duration to assess the sustainability of the effect or the long-term benefits in terms of effect on symptoms, reduction of morbidity or impact on the economic aspects of the disease. The proposed treatment or intervention should also be inexpensive if we want them to be disseminated to a wide population and to be compatible with health economics policies, given the demographic importance of the disease and, more significantly, if we continue with preventive actions for potentially larger numbers of subjects. Treatments should also be devoid of major side effects and tolerance must be compatible with their distribution to an ageing population, by definition frail, with much comorbidity and many 
associated medications. The disadvantages of this approach are the exact corollary of the arguments for its ease of implementation. Recruitment on the basis of clinical criteria, only applicable in large populations, induces diagnostic uncertainty inherent to their low specificity, especially in the early stages of the disease. Thus, we have seen recently in a phase III study testing the efficacy of monoclonal antibodies that, even when selected in expert centers, a significant number of patients showed no evidence of the pathophysiological mechanism of the disease, as assessed by amyloid imaging [6,7]. This uncertainty makes risky the proposal of a treatment specifically directed to a supposed process, and limits this strategy to symptoms of more general determinism or to prevention through action on risk factors acting on a common pathway. Finally, there remains the question of the clinical effectiveness of the intervention and the size of the desired effect. This has given rise to a debate, not yet fully resolved, on the currently available symptomatic treatments. Lessons from epidemiology lead us to believe that this type of strategy is more suited to prevention through potentially significant impacts of even small effect size [8].

The second option of providing a targeted drug intervention in highly selected subjects has shown efficacy in other major disease areas. In the field of oncology, the development of tailored therapies, developed in a proactive and extensive research effort, has led to major advances in the treatment and prognosis of certain cancers. In the field of Alzheimer's disease, this approach concerns essentially the pathophysiological medications currently under investigation. Anti-amyloid (for example, immunotherapy with monoclonal antibodies), inhibition of $\gamma$ - and $\beta$-secretases, or drugs acting on the metabolism of tau are therapies targeted to a specific point of impact identified by recent advances in basic research. If the pathophysiological hypothesis is correct, these targeted strategies can be particularly effective provided that the patient's pathology is well connected to the target process, with evidence provided by the presence of a validated biomarker. These interventions are thus inextricably linked to the application of available biomarkers, protein assays in cerebrospinal fluid and amyloid imaging [9]. The advantage of this type of therapeutic strategy is to provide the best chance of success by using a drug directed at a known causative target in a given patient. Recent large therapeutic trials on antibodies have shown that these drugs, when applied to large populations, show generally insignificant efficacy but with encouraging results in well identified subpopulations, especially in the early stages of disease [10]. The disadvantage of this approach is the difficulty in obtaining samples for determining biomarker presence in practice because of the acceptability of methods of extraction (especially lumbar puncture) and cost (for example, amyloid imaging) [11]. The investment required for the recruitment of subjects must be carefully weighed against the expected therapeutic effect and potential side effects of proposed treatments $[12,13]$. The development of new biomarkers or improvement of existing techniques together with standardization of measurements should facilitate this process [14]. As this strategy is reserved, by definition, to limited populations, it is questionable in terms of pharmacoeconomics and, if proven effective, must be assessed in thorough studies. In addition, the selection of study participants for these procedures requires a significant change in the attitude of the general population with regard to Alzheimer's disease and therapeutic innovation. Today we see the difficulties of recruiting for clinical trials involving new therapeutic approaches and requiring complex examinations for selection and safety. The proactivity

Table 1 Treatment strategies in Alzheimer's disease

\begin{tabular}{|c|c|c|}
\hline Drug/intervention & Population & Selected volunteers \\
\hline \multirow[t]{3}{*}{ Advantages } & Large number of treated subjects & Targeted intervention \\
\hline & \multirow[t]{2}{*}{ Easier to identify (no biomarker required) } & Evidenced pathophysiological mechanisms (biomarkers) \\
\hline & & Larger benefit at the individual level \\
\hline \multirow[t]{4}{*}{ Disadvantages } & $\begin{array}{l}\text { Cost of intervention (necessity of large intervention } \\
\text { in terms of subject number and duration to obtain } \\
\text { a benefit at the population level) }\end{array}$ & Limited number of subjects \\
\hline & Frail population & Necessity of biomarkers (availability, acceptability, standardization) \\
\hline & Diagnostic uncertainty & Cost of biomarkers (for example, amyloid imaging) \\
\hline & Variability of size effect & $\begin{array}{l}\text { Strength of evidence is highly dependent on the validity } \\
\text { of pathophysiological hypothesis }\end{array}$ \\
\hline \multirow[t]{3}{*}{$\begin{array}{l}\text { Proposal for future } \\
\text { treatment strategies }\end{array}$} & $\begin{array}{l}\text { Symptomatic treatments for clinical (mild to severe) } \\
\text { stages of Alzheimer's disease }\end{array}$ & $\begin{array}{l}\text { Tailored intervention for prodromal and very mild } \\
\text { Alzheimer's disease }\end{array}$ \\
\hline & Prevention (multidomain intervention) & \multirow{2}{*}{$\begin{array}{l}\text { This kind of targeted prevention study using expensive } \\
\text { treatment interventions and outcome measures could serve } \\
\text { as proof of concept to stimulate cheaper interventions }\end{array}$} \\
\hline & $\begin{array}{l}\text { Biomarkers could be considered as outcome for evaluating } \\
\text { the impact on disease-relevant pathophysiology }\end{array}$ & \\
\hline
\end{tabular}


that promoted cancer research should be copied in the field of neurodegenerative diseases. This requires the development of truly effective treatments with sufficient safety as well as an improvement of the technical means of diagnosis.

\section{Conclusion}

In conclusion, we can try to schematize the future of Alzheimer's disease treatments (Table 1): symptomatic treatments should retain a place in the advanced stages of the disease since their actions on these symptoms, even if not modifying the course of disease, are critical for improving patients' comfort and reducing the burden felt by caregivers, especially those facing behavioral disorders. However, many patients with late onset dementia have mixed pathology, including Alzheimer's disease and vascular disease; therefore, lifestyle and medication interventions to address risk factors might be beneficial. In mild or prodromal stages, the opportunity to act on specific pathophysiological targets should be considered. These targeted and tailored therapies have the greatest chance to be active in the early stages of disease, in the context of heterogeneous pathological mechanisms to be specified by reliable and accessible biomarkers. Finally, interventional approaches in large populations seem particularly appropriate for prevention strategies. However, drugs or interventions based on observational/epidemiological studies for Alzheimer's disease or dementia have not met with success. Validated interventions that are inexpensive and readily acceptable, such as physical and cognitive exercise or prevention of cardiovascular and metabolic risk factors, are a first level of action to consider, ideally integrated in multidomain intervention programs encompassing the synergistic action of these strategies [15].

\section{Competing interests}

The authors declare that they have no competing interests.

Published: 11 December 2013

\section{References}

1. Andrieu S, Coley N, Aisen P, Carrillo MC, DeKosky S, Durga J, Fillit H, Frisoni GB, Froelich L, Gauthier S, Jones R, Jönsson L, Khachaturian Z, Morris JC, Orgogozo JM, Ousset PJ, Robert P, Salmon E, Sampaio C, Verhey F, Wilcock $G$, Vellas B: Methodological issues in primary prevention trials for neurodegenerative dementia. J Alzheimers Dis 2009, 16:235-270.

2. Hampel H, Lista S: Use of biomarkers and imaging to assess pathophysiology, mechanisms of action and target engagement. J Nutr Health Aging 2013, 17:54-63.

3. Mangialasche F, Solomon A, Winblad B, Mecocci P, Kivipelto M: Alzheimer's disease: clinical trials and drug development. Lancet Neurol 2010, 9:702-716.

4. Delrieu J, Piau A, Caillaud C, Voisin T, Vellas B: Managing cognitive dysfunction through the continuum of Alzheimer's disease: role of pharmacotherapy. CNS Drugs 2011, 25:213-226.

5. McKhann GM, Knopman DS, Chertkow H, Hyman BT, Jack CR Jr, Kawas CH, Klunk WE, Koroshetz WJ, Manly JJ, Mayeux R, Mohs RC, Morris JC, Rossor MN, Scheltens P, Carrillo MC, Thies B, Weintraub S, Phelps CH: The diagnosis of dementia due to Alzheimer's disease: recommendations from the National
Institute on Aging-Alzheimer's Association workgroups on diagnostic guidelines for Alzheimer's disease. Alzheimers Dement 2011, 7:263-269.

6. Aisen PS, Vellas B: Passive immunotherapy for Alzheimer's disease: what have we learned, and where are we headed? J Nutr Health Aging 2013, 17:49-50.

7. Vellas B, Carrillo MC, Sampaio C, Brashear HR, Siemers E, Hampel H, Schneider LS, Weiner M, Doody R, Khachaturian Z, Cedarbaum J, Grundman M, Broich K, Giacobini E, Dubois B, Sperling R, Wilcock GK, Fox N, Scheltens P, Touchon J, Hendrix S, Andrieu S, Aisen P, EU/US/CTAD Task Force Members: Designing drug trials for Alzheimer's disease: What we have learned from the release of the phase III antibody trials: a report from the EU/US/CTAD Task Force. Alzheimers Dement 2013, 9:438-444.

8. Brookmeyer R, Gray S, Kawas C: Projections of Alzheimer's disease in the United States and the public health impact of delaying disease onset. Am J Public Health 1998, 88:1337-1342.

9. Ossenkoppele R, Prins ND, van Berckel BNM: Amyloid imaging in clinical trials. Alzheimers Res Ther 2013, 5:36.

10. Tayeb HO, Murray ED, Price BH, Tarazi Fl: Bapineuzumab and solanezumab for Alzheimer's disease: is the 'amyloid cascade hypothesis' still alive? Expert Opin Biol Ther 2013, 13:1075-1084.

11. Mitka M: PET imaging for Alzheimer disease: are its benefits worth the cost? JAMA 2013, 309:1099-1100.

12. Doody RS, Raman R, Farlow M, Iwatsubo T, Vellas B, Joffe S, Kieburtz K, He F, Sun X, Thomas RG, Aisen PS, Alzheimer's Disease Cooperative Study Steering Committee, Siemers E, Sethuraman G, Mohs R, Semagacestat Study Group: A phase 3 trial of semagacestat for treatment of Alzheimer's disease. N Engl J Med 2013, 369:341-350.

13. Gilman S, Koller M, Black RS, Jenkins L, Griffith SG, Fox NC, Eisner L, Kirby L, Rovira MB, Forette F, Orgogozo JM, AN1792(QS-21)-201 Study Team: Clinical effects of Abeta immunization (AN1792) in patients with AD in an interrupted trial. Neurology 2005, 64:1553-1562.

14. Frisoni GB, Bocchetta M, Chételat G, Rabinovici GD, de Leon MJ, Kaye J, Reiman EM, Scheltens P, Barkhof F, Black SE, Brooks DJ, Carrillo MC, Fox NC, Herholz K, Nordberg A, Jack CR Jr, Jagust WJ, Johnson KA, Rowe CC, Sperling RA, Thies W, Wahlund LO, Weiner MW, Pasqualetti P, Decarli C, For ISTAART's Neurolmaging Professional Interest Area: Imaging markers for Alzheimer disease: which vs how. Neurology 2013, 81:487-500.

15. Carrié I, Van Kan GA, Gillette-Guyonnet S, Andrieu S, Dartigues JF, Touchon J, Dantoine T, Rouaud O, Bonnefoy M, Robert P, Cuffi MN, Bories L, Bordes S, Gasnier Y, Desclaux F, Sudres K, Pesce A, Vellas B: Recruitment strategies for preventive trials. The MAPT study (MultiDomain Alzheimer Preventive Trial). J Nutr Health Aging 2012, 16:355-359.

\section{doi:10.1186/alzrt228}

Cite this article as: Ousset et al: Should interventions to treat or prevent Alzheimer's disease be tested in a population or as targeted treatment of highly selected study participants?. Alzheimer's Research \& Therapy 2013 5:62. 